\title{
Establishment and characterization of a cell line, EH-GB2, derived from hepatic metastasis of gallbladder cancer
}

\author{
JING-HAN WANG ${ }^{1 *}$, LIN-FANG LI ${ }^{2 *}$, YONG YU ${ }^{1}$, BIN LI $^{1}$, HUA-JUN JIN ${ }^{2}$, \\ DONG-HAO SHEN ${ }^{2}$, JIANG LI ${ }^{2}$, XIAO-QING JIANG ${ }^{1}$ and QI-JUN QIAN ${ }^{2}$ \\ ${ }^{1}$ Department of First Biliary Surgery, and ${ }^{2}$ Laboratory of Viral and Gene Therapy, Eastern Hepatobiliary \\ Surgical Hospital and Institute, The Second Military University, Shanghai 200438, P.R. China
}

Received September 12, 2011; Accepted October 25, 2011

DOI: $10.3892 /$ or.2011.1570

\begin{abstract}
Gallbladder cancer is a fatal neoplasia with an extremely low survival rate. Liver invasion and metastasis are the most common causes of death; however, the metastatic mechanism is still unclear, and no effective treatment methods are available. To provide comprehensive and profound approaches in investigating the metastatic mechanism and treatment methods, new cell lines derived from liver metastasis are urgently needed. A hepatic metastasis lesion was obtained from a 65-year-old patient, and was treated using a primary culture method to establish a novel gallbladder cancer cell line. Different in vitro/in vivo methods were used to characterize the phenotypes of this cell line. The gallbladder cancer cell line was named EH-GB2, with a roughly 48-h doubling time. The cell line represents stronger colony formation and migration abilities than the control group. The cells showed complicated chromosomal abnormalities. EH-GB2 cells showed epithelial-to-mesenchymal transition (EMT) and the mRNA expression levels of E-cadherin and integrin were decreased, and those of vimentin, Snail, Twist, matrix metalloproteinase-1 (MMP-1) and MMP-2 were increased in comparison with control cells. The in vivo study demonstrated that EH-GB2 cells show significant tumorigenicity in nude mice. The EH-GB2 established gallbladder cancer cell line is useful for future studies of gallbladder cancer development, progression, metastasis and therapy.
\end{abstract}

Correspondence to: Dr Qi-Jun Qian, Laboratory of Viral and Gene Therapy, Eastern Hepatobiliary Surgical Hospital and Institute, The Second Military University, Shanghai 200438, P.R. China

E-mail: qianqj@sino-gene.cn

Dr Xiao-Qing Jiang, Department of First Biliary Surgery, Eastern Hepatobiliary Surgical Hospital and Institute, The Second Military University, Shanghai 200438, P.R. China

E-mail: jxq1225@sina.com

${ }^{*}$ Contributed equally

Key words: gallbladder cancer, EH-GB2, hepatic metastasis, cell line, epithelial-mesenchymal transition

\section{Introduction}

Gallbladder cancer (GBC) is the most common cancer of the bile duct system and the fifth most deadly cancer of the digestive system (1). The incidence of GBC in China, Thailand, Chile and Northern India is higher compared with the United States and European countries (2).

According to our clinical experience, radical resection is still the most effective treatment for GBC (3), however, the overall survival rate is still extremely poor (4), due to the early metastasis, late diagnosis and insensitivity to chemoradiation therapy (5). Another dismal problem is that GBC is more prone to recurrence and metastasis even after curative resection. Accordingly, the liver is the most favorable site for the tumor cells to metastasize yet, the mechanism remains unclear. Therefore, intense study of the mechanism and intervention of GBC recurrence and metastasis is of special significance to human health. In order to gain a better understanding of the mechanisms and biology of GBC metastasis and new clinical strategies, ideal tools are essential. So far, there has been no report of the establishment of GBC cell lines derived from hepatic metastasis.

In present study, we established the first GBC cell line derived from liver metastatic lesions, which may prove to be an efficient tool for further investigation of the mechanism and treatment of this malignant disease.

\section{Materials and methods}

Establishment of the EH-GB2 cell line and cell culture. The cell line EH-GB2 was established from a tumor metastatic specimen which was surgically obtained from patients with GBC accompanied with liver metastasis. Informed consent was obtained from this patient. After rinsing twice with sterile phosphate-buffered saline (PBS) containing antibiotics, the tumor specimen was minced into small fragments having a diameter of $1 \mathrm{~mm}$ using a scalpel. The fragments were then enzymatically disaggregated after incubating with collagenase type IV solution at $37^{\circ} \mathrm{C}$ in a humidified atmosphere containing $5 \% \mathrm{CO}_{2}$. After about $1 \mathrm{~h}$ of incubation, a single cell was isolated and $5 \mathrm{ml}$ fetal calf serum (FBS) (Gibco, Grand Island, NY, USA) was added to terminate the digestion. Then the digested tumor fragments and fluid was filtrated with a 
Table I. Primer sequences.

\begin{tabular}{ll}
\hline Primer name & \multicolumn{1}{c}{ Primer sequence (5'-3') } \\
\hline Snail & F: TTCTTCGCTACTGCTGCG \\
& R: GGGCAGGTATGGAGAGGAAGA \\
E-cadherin & F: TGATGCCCCCAATACCCCAG \\
& R: CTGTGGAGGTGGTGAGAGAG \\
Integrin $\alpha 5$ & F: ACCAAGGCCCCAGCTCCATTAG \\
& R: GCCTAACACTGCAGGCTAAATG \\
Twist & F: GGGAGTCCGCAGTCTTACGA \\
& R: CTAGTGGGACGCGGAC \\
MMP-2 & F: CACCATCGCCCATCATCA \\
& R: TGGATTCGAGAAAACGCAGC \\
MMP-9 & F: GGGACGGCAATGCTGAT \\
& R: CGCCACGAGGAACAAACT \\
VEGF & F: TTGCTTGCTCTACCTCCAC \\
& R: ASAATGCTTTCTCCGCTCTG \\
GAPDH & F: TGGTATCGTGGAAGGACTCATGAC \\
& R: ATGCCAGTGAGCTTCCCGTTCAGC
\end{tabular}

200 mesh sieve, and the filtrate was centrifuged at 1,000 r/min for $5 \mathrm{~min}$. The supernatant was removed and the remaining cells were resuspended in Dulbecco's modified Eagle's medium (DMEM) (Gibco) supplemented with heat-inactivated $15 \%$ FBS, seeded into 6 -well culture plates, and cultivated at $37^{\circ} \mathrm{C}$ in a humidified atmosphere of $5 \% \mathrm{CO}_{2}$ in the air. The growth medium was replaced every 2-3 days, and the plate was regularly checked for epithelial cells and fibroblast outgrowth. If fibroblast growth was observed during primary cultures, differential trypsinisation was used to obtain a pure tumor-cell population. The cell line was cultured for $>60$ passages.

Morphology and ultrastructure of the EH-GB2 cell line. Cells in flasks were photographed directly without staining under a phase contrast microscope. For electron microscopic analysis, the monolayer cells were harvested from flasks and pelleted. The pellet was fixed with $2.5 \%$ glutaraldehyde in $1 \mathrm{ml}$ PBS, pH 7.2, washed in $0.1 \mathrm{ml}$ PBS, and then post-fixed in $2 \%$ osmium tetraoxide after dehydration in ethanol; then the samples were embedded in Epon resin. Ultrathin sections were stained with uranyl acetate and lead citrate, and examined under a Hitachi1 H-800 (Hitachi, Tokyo, Japan) electron microscope.

Cell growth property and cell cycle analysis. The assay of the cell growth curve was performed as previously described (6), with some modifications. The GBC-SD cell line which was derived from primary gallbladder cancer was selected for a positive control. Cells were plated into 96-well plates at 4,000 cells/well, cultured in 15\% FBS DMEM for various durations, and the cell numbers were measured by a MTT assay according to the protocol provided by the MTT manufacturer. The doubling times were determined from the growth curve.
Cell cycle analysis was performed after fluorescence labeling of cellular deoxyribonucleic acid (DNA) by propidium iodide (Invitrogen). Cells $\left(1 \times 10^{6}\right)$ in the exponential growth phase were harvested and fixed with cold $70 \%$ alcohol after rinsing with cold PBS twice, incubation for $4 \mathrm{~h}$ at $4^{\circ} \mathrm{C}$ environment. After being centrifuged at $1,000 \mathrm{r} / \mathrm{min}$ for $3 \mathrm{~min}$ the cells were rinsed with cold PBS once, and resuspended in $1 \mathrm{ml}$ of propidium iodide stain (50 $\mathrm{ml} / \mu \mathrm{M}$ propidium iodide, $100 \mu \mathrm{g} / \mathrm{ml} \mathrm{RNase}$ ) and incubated for $30 \mathrm{~min}$ at room temperature. Cell cycle analysis was performed by flow cytometry.

Soft agar assay. Clone formation of different cell clones in soft agar could be used to describe their growth capabilities. A single-cell suspension was made and the number was controlled at $400 / \mathrm{ml}$. Agar $(0.6 \%)$ was prepared by mixing with DMEM and introduced into 6-well plates as the lower layer. Agar was mixed cell suspension and then the mixture was seeded in the same 6-well plates as the upper layer. Every well contained 20 cells. The plates were incubated at $37^{\circ} \mathrm{C}$ in a humidified incubator containing $5 \% \mathrm{CO}_{2}$. Fourteen days later the number of cell colonies was counted under a microscope and the clone formation rates were calculated using the following formula: Clone formation rate $(\%)=$ (number of colonies/number of cells inoculated) x $100 \%$.

Total RNA isolation and RT-PCR. Total ribonucleic acid (RNA) was extracted using the TRIzol reagent (Invitrogen) according to the manufacturer's instructions. RNA quality and quantity was determined by spectrophotometery and gel electrophoresis. Total RNA ( $2 \mathrm{mg}$ ) was used for cDNA synthesis with the Quantscript RT kit [Tiangen Biotech (Beijing) Co., Ltd., Beijing, China]. Reverse transcriptase polymerase chain reaction (RT-PCR) analysis was performed with each primer (Table I) as previously described $(7,8)$. All reactions were repeated three times.

Western blotting. Whole cell lysate of the cells was prepared by sonicating the cells lysed in $62 \mathrm{mM}$ Tris- $\mathrm{HCl}$ and $2 \%$ SDS. In another set of experiments, cytoplasmic and nuclear proteins were also extracted. The protein concentration was measured by the BCA protein assay (Pierce). Total proteins were fractionated using SDS-PAGE and transferred onto a nitrocellulose membrane for Western blotting as described before with a slight modification (9).

Chromosome analysis. Cells were karyotyped using a standard air-dried method after treatment with a final concentration of $0.05 \mathrm{mg} / \mathrm{ml}$ colcemid for $2 \mathrm{~h}$ when the cells were in an exponential growth phase. They were analyzed using trypsin $G$ banding. A total of 50 metaphase spreads were counted to determine the modal number. Karyotyping was performed according to the International System for Human Cytogenetic Nomenclature (2005). Chromosome analysis was carried out on the cell line at the passage 30 .

Tumor marker detection. As previously described, $10^{5}$ tumor cells was cultured in DMEM with $15 \%$ FBS medium for $24 \mathrm{~h}$ before the conditioned medium was collected and centrifuged at $1,800 \mathrm{r} / \mathrm{min}$ for $10 \mathrm{~min}$. The supernatant was then collected 

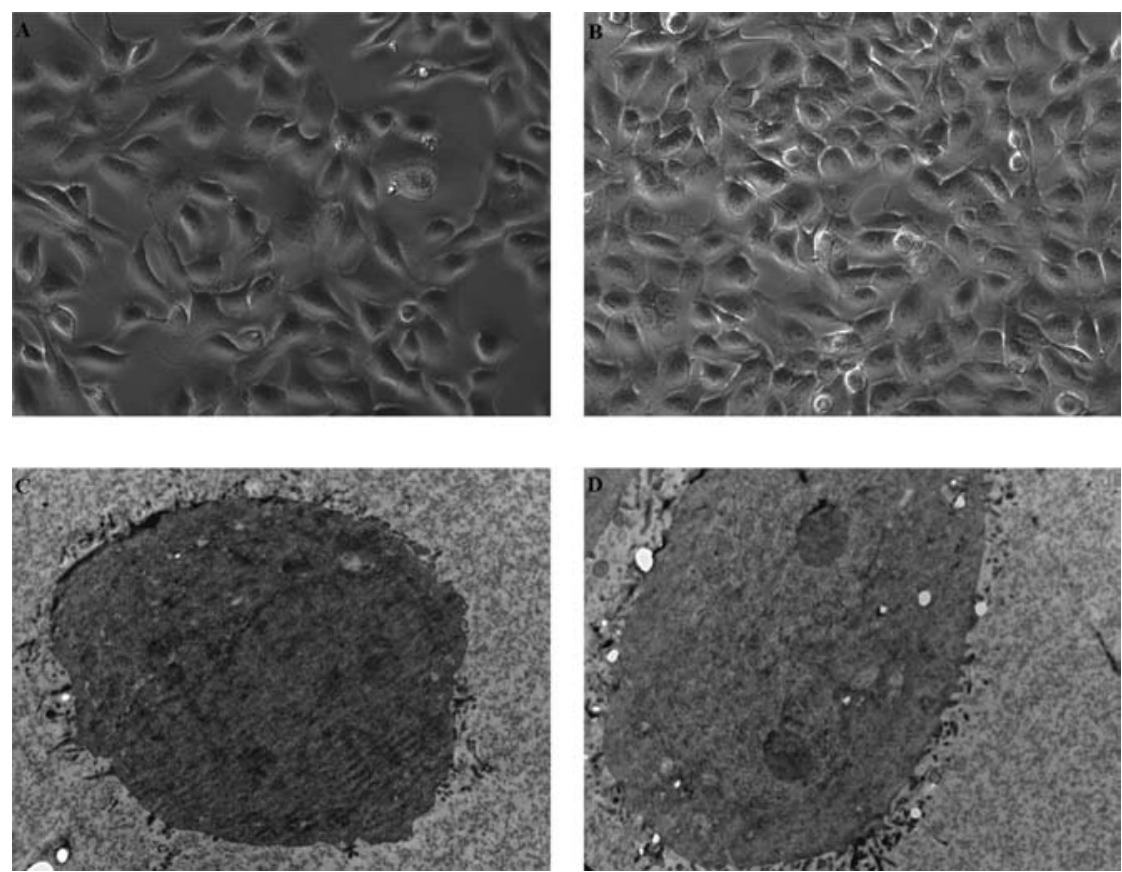

Figure 1. Morphology of EH-GB2 cells. (A and B) Cultured cells with polygonal shapes have typical epithelial morphology in passage 14 and passage 34 (light microscopy, x20). (C and D) Transmission electron microscopy (TEM) of EH-GB2 displaying intense microvilli on the cell surface, and incremental organelles, such as endoplasmic reticulum mitochondria, ribosomes and nuclei (TEM; x9000).

for detection of CA19-9, carcinoembryonic antigen (CEA) and $\alpha$-fetoprotein (AFP) by using an ELISA kit (R\&D Systems) (10).

Wound scratch assay. The wound scratch assay was performed as previously described (11). Cells were plated in 6-well plates. After the cells reached semiconfluence, a wound was created in the center of the cell monolayer by a sterile plastic pipette tip. Immediately thereafter, the cells were washed with PBS to remove floating cellular debris and reincubated for an additional $48 \mathrm{~h}$ with DMEM medium supplemented with $15 \% \mathrm{FBS}$ at $37^{\circ} \mathrm{C}$. The migration cell number was counted in four random scratched fields. The culture was performed in triplication.

Tumorigenicity in nude mice. Tumorigenic assays were performed as previously described. The study protocol on mice was approved by the Second Military Medical University Experimental Animal Care Commission. Briefly, cells of passage 28 were prepared to determine their tumorigenicity in nude mice. Cultured cells $\left(2 \times 10^{6} / \mathrm{ml}\right)$ were harvested, washed, resuspended in $0.1 \mathrm{ml}$ of complete DMEM, and injected subcutaneously into the right flanks of two 4-5-week-old male nude mice. Animals were examined every week for the development of tumors. Tumor-bearing mice were sacrificed. Tumor tissue was excised, fixed in $10 \%$ formalin, and processed for routine histopathological examination.

Statistical analysis. The statistical significance of differential findings between experimental groups and control was determined by Student's t-test. Values of $\mathrm{P}<0.05$ were considered statistically significant.

\section{Results}

The new gallbladder cancer cell line, designated EH-GB2 (Eastern Hepatobiliary Surgery Hospital, Gallbladder Cancer), was successfully established in vitro with a fresh aseptic specimen derived from hepatic metastasis of gallbladder cancer. In the following culture, we succeeded in freezing and thawing cells and subculturing for $>60$ generations in DMEM supplemented with $15 \%$ FBS.

In vitro characteristics of EH-GB2 cells. The EH-GB2 cell line grew as an adherent monolayer with characteristic epithelial morphology and showed no significant differences in successive culturing (Fig. 1A and B). Cells in passage 14 and 34 were observed under light microscopy. Ultrastructure analysis was carried out to verify the epithelial characteristics of EH-GB2. Transmission electron microscopy observation revealed polygonal EH-GB2 cells. Intense microvilli were located on the cell surface. Furthermore, cells had irregular organelles, such as endoplasmic reticulum mitochondria, ribosomes and nuclei (Fig. 1C and D). The growth property of the EH-GB2 cell line was assayed by the MTT method using GBC-SD cells as a positive control (Fig. 2A). Compared with GBC-SD, the EH-GB2 cell line has a more vigorous growth tendency and has a doubling time of about $48 \mathrm{~h}$. We also examined the cell cycle of EH-GB2 cell line and found that nearly $35 \%$ of the cells were in the G2-S-M phase (Fig. 2B). We determined the levels of CA19-9, CEA and AFP, and subsequently found that CA19-9 was dramatically increased and the antigens AFP and CEA showed normal levels in the culture supernatant. However, these antigens were all in a normal range in mouse serum (Fig. 2C). The expression levels of CA19-9 present an inconsistency between the supernatant and mouse serum. 

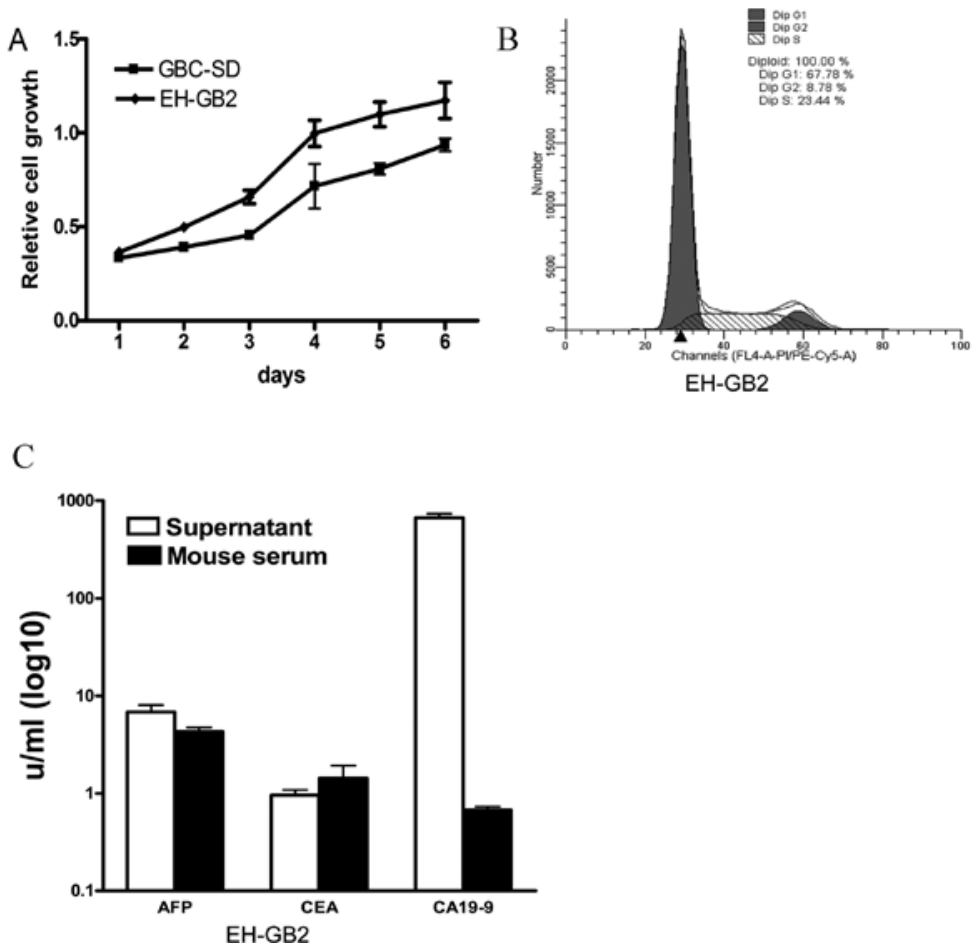

Figure 2. The characteristics of EH-GB2 and GBC-SD cell lines were assayed. (A) Cells were seeded on 96-well plates with a concentration of 4,000 cells/well. Data was obtained by the MTT assay each day to depict a growth curve. (B) Cell cycle of EH-GB2. Cells were harvested for cell cycle analysis by FCS after propidium iodide staining. (C) Tumor relative marker assay.

A

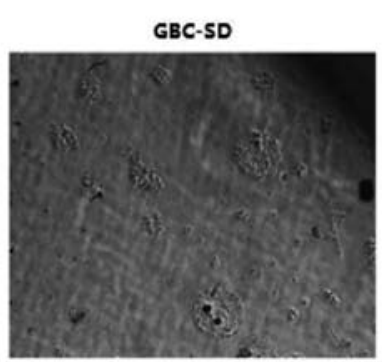

GBC-SD

B

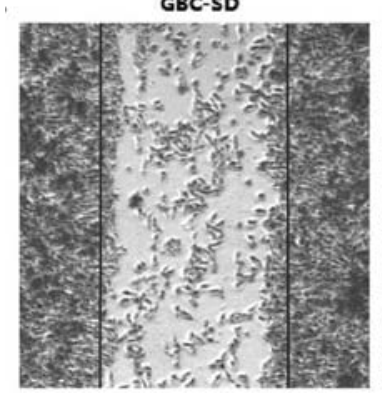

EH-GB2

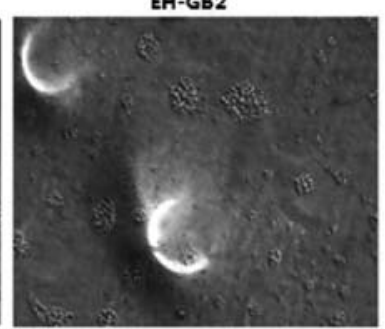

EH-GB2

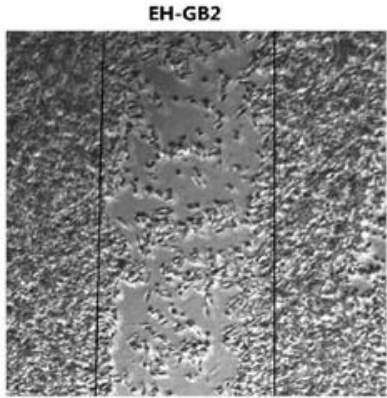

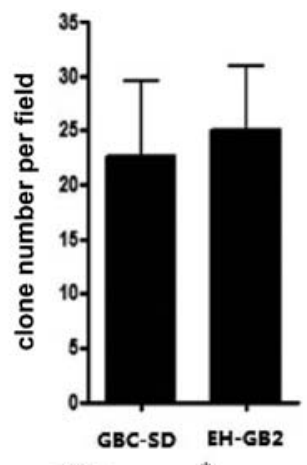

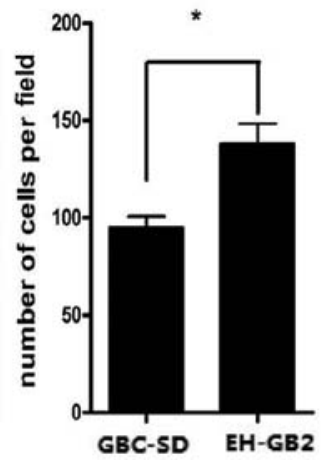

Figure 3. The motility of EH-GB2 cells in vitro. (A) Anchorage-independent growth. EH-GB2 and GBC-SD cells were plated in $2.5 \%$ agar with $15 \%$ FBS complemented for 2 weeks to test the formation of colonies. (B) Migration activity. Representative phase-contrast images of the wound-healing assay show the migrating cells in the wound margin. The number of migrating EH-GB2 cells was greater than that of GBC-SD cells. Dotted line, wound margin.

Clone formation and migration. In order to assess the anchorage-independent growth abilities of EH-GB2 cells, a clone formation assay was performed. EH-GB2 cells showed stronger anchorage-independent growth abilities compared to GBC-SD (Fig. 3A). Fig. 3B shows representative phasecontrast images of the in vitro wound-healing assay. The number of migrating EH-GB2 cells was greater than that of GBC-SD cells $(\mathrm{P}<0.05)$. 


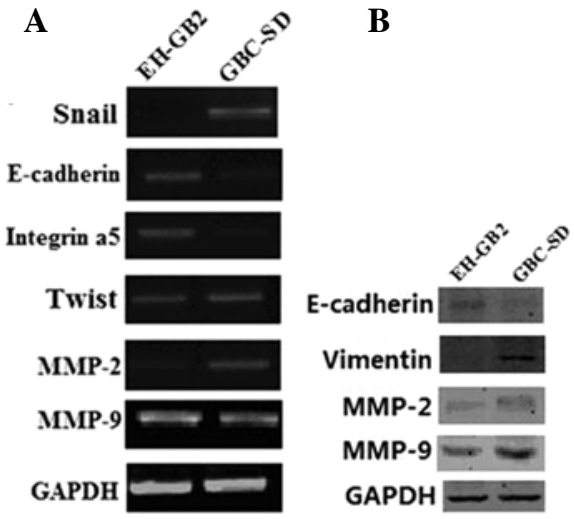

Figure 4. Expression of metastasis-related genes in the EH-GB2 cell line. (A) Both GBC-SD and EH-GB2 cells were harvested for RNA purification and RT-PCR targeting of E-cadherin, Snail, Twist, intergrin $\alpha 5$, MMP-2, and -9. (B) Western blotting was carried out to examine E-cadherin, vimentin, MMP-2, 9 and GAPDH protein expressions. GAPDH protein levels were used to normalize the Western blot reactions.

Tumor metastasis relative gene expression analysis. Metastasis is a complex process that involves multiple alterations of many related genes. Here, we assumed that the epithelial mesenchymal transition (EMT) plays essential roles in the metastatic potential of EH-GB2. The epithelial marker E-cadherin was down-regulated in EH-GB2, and the mesenchymal marker vimentin was up-regulated (Fig. 4). The expressions of Snail, Twist, MMP-2 and MMP-9 in EH-GB2 were higher than that in GBC-SD. These gene expression trends were consistent by RT-PCR (Fig. 4A) and by Western blot analyses (Fig. 4B).

Karyotype of the EH-GB2 cell line. Complicated karyotypes were revealed in the EH-GB2 cell line, which included gains, losses, translocations, and other abnormalities, by G-band analysis (Fig. 5). The number of chromosomes ranged between 88 and 105, with a median of 98. The arrowheads indicate rearranged chromosomes. Several abnormalities were detected with the highest frequencies, observed for der(1) $\mathrm{t}(1 \mathrm{qter} \rightarrow \mathrm{p} 34:: 1 \mathrm{q} 25 \rightarrow \mathrm{qter}), \operatorname{del}(1)(1 \mathrm{pter} \rightarrow \mathrm{q} 22:: 1 \mathrm{q} 32 \rightarrow \mathrm{qter}), \mathrm{i}(2)$ $($ qter $\rightarrow$ p10::q10 $\rightarrow$ qter $), \operatorname{del}(6)($ qter $\rightarrow$ p21: $), \operatorname{add}(9)($ pter $\rightarrow$ q10::?), $\operatorname{del}(9)($ qter $\rightarrow$ p12: $)$, add(15) $(15$ qter $\rightarrow$ p10 ::22p10 $\rightarrow$ qter $)$, der(?) and dmin were found in all analyzed cells (Tables II and III). In addition, some other abnormalities, $\mathrm{i}(2)(\mathrm{pter} \rightarrow \mathrm{p} 10:: \mathrm{q} 10 \rightarrow$ pter $)$ $(28 / 30)$, del(11) $($ pter $\rightarrow$ q14: $)$ and $\operatorname{der}(?)(29 / 30)$, with high frequency were also found (Tables II and III).

Histological examination. At 3 weeks after subcutaneous injection of EH-GB2 cells in mice, tumors were found at the site of inoculation. The subcutaneous tumor was removed for histological examination, and the results were compared with the hepatic metastasis tumor. Both hepatic metastasis and subcutaneous tumors were characterized by typical gallbladder carcinoma (H\&E) features (Fig. 6A-D) and all showed poor differentiation. Immunohistochemical results demonstrate positive expression of CK19 in subcutaneous tumors, but CA19-9 is negatively expressed (Fig. 6E-H).

\section{Discussion}

Carcinoma of the gallbladder is a highly fatal disease with poor prognosis. It is the most common malignant lesion of the biliary tract and the fifth most common among malignant neoplasms of the digestive tract. It is reported that the 5-year survival for cancers of the gallbladder lies between 0 and $10 \%$ in most reported series (12). Liver, an adjacent organ of the gallbladder, is the most frequent site of gallbladder cancer invasion and metastasis which results in the death of patients. According to the previous reports, there are already many established gallbladder cancer cell lines, and most of them are derived from primary tumors, metastasis or ascites, but rarely form hepatic metastasis.

At present study, a gallbladder cancer cell line (EH-GB2), derived from hepatic metastasis, was established from a Chinese patient. The EH-GB2 cells grew as an adherent monolayer with characteristic epithelial morphology; and with a population doubling time of approximately $48 \mathrm{~h}$. Cultured cells maintained consistent morphology from the primary culture to the following subculture passages. The EH-GB2 cells had been grown continuously for approximately 5 months, undergoing $>40$ passages; and growth continued even after recovery from cry preservation. The EH-GB2 cells also exhibited an ability to form colonies in soft agar. Here, the EH-GB2 cell

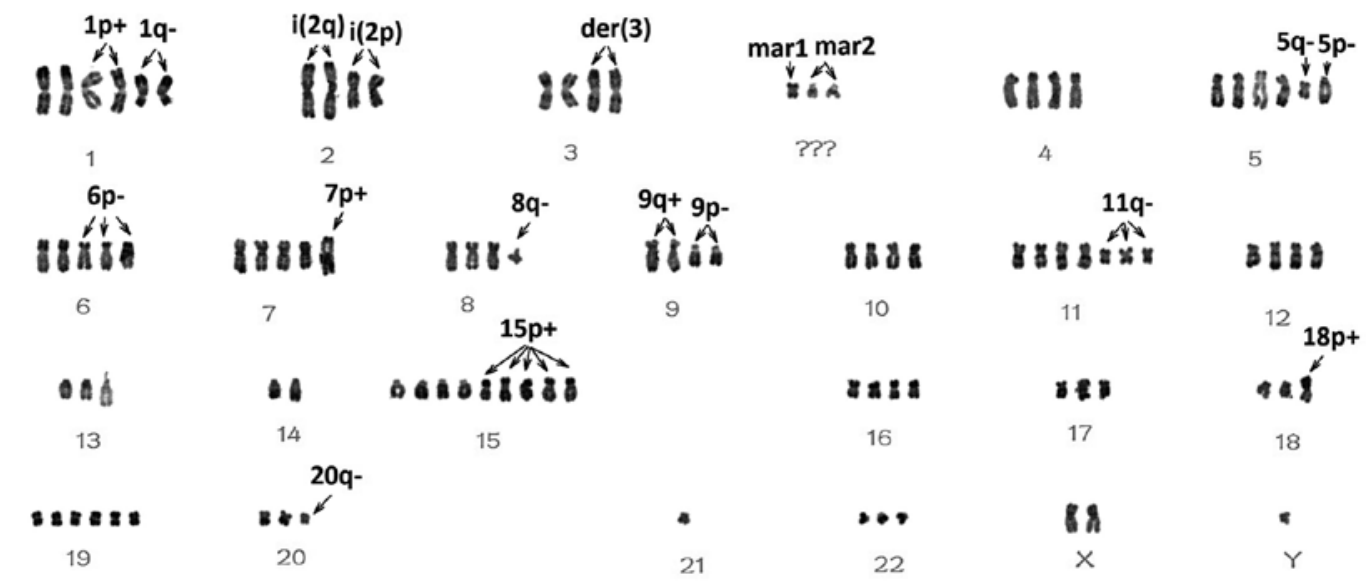

Figure 5. Karyotype analysis of the EH-GB2 cell line (passage 35). The karyotype of the EH-GB2 cell line shows abnormalities in both the number and the structure. 
Table II. Frequency of abnormal chromosomes in 30 karyotypes analyzed (passage 35).

\begin{tabular}{|c|c|c|c|c|c|c|c|c|c|c|c|}
\hline \multirow[b]{2}{*}{ Chromosome } & \multicolumn{5}{|c|}{ Extra chromosomes } & \multicolumn{6}{|c|}{ Abnormal chromosomes (markers) } \\
\hline & $-2 \times 2$ & +3 & +4 & +5 & $+7 \times 2$ & $+\mathrm{M} 23$ & $+\mathrm{M} 1 * 2$ & $+\mathrm{M} 2 * 2$ & $+\mathrm{M} 4^{*} 2$ & $+\mathrm{M} 5^{*} 2$ & $+\mathrm{M} 6$ \\
\hline Frequency & 30 & 20 & 29 & 28 & 30 & 23 & 30 & 30 & 30 & 28 & 19 \\
\hline Chromosome & $+8 \times 2$ & $-9 \times 2$ & $+10 \times 3$ & +11 & $+12^{*} 2$ & $+\mathrm{M} 7$ & +M8 & $+\mathrm{M} 9$ & $+\mathrm{M} 10$ & $+\mathrm{M} 11$ & $+\mathrm{M} 12$ \\
\hline Frequency & 29 & 30 & 29 & 30 & 29 & 26 & 16 & 30 & 11 & 20 & 30 \\
\hline Chromosome & +13 & $+14^{*} 2$ & $+16^{*} 2$ & +18 & $+19^{*} 4$ & $+\mathrm{M} 13^{*} 2$ & $+\mathrm{M} 14$ & $+\mathrm{M} 15$ & $+\mathrm{M} 16$ & $+\mathrm{M} 17$ & $+\mathrm{M} 19 * 3$ \\
\hline Frequency & 25 & 30 & 24 & 21 & 19 & 30 & 21 & 15 & 29 & 26 & 30 \\
\hline Chromosome & +20 & -21 & +22 & $+\mathrm{X}$ & $-\mathrm{Y}$ & $+\mathrm{M} 20$ & $+\mathrm{M} 21$ & $+\mathrm{M} 22$ & $+\mathrm{M} 23$ & $+\mathrm{M} 24$ & $+\mathrm{M} 25$ \\
\hline Frequency & 25 & 30 & 18 & 20 & 18 & 19 & 11 & 24 & 21 & 29 & 30 \\
\hline Chromosome & & & & & & $+\mathrm{M} 26$ & & & & & \\
\hline Frequency & & & & & & 30 & & & & & \\
\hline
\end{tabular}

Table III. Abnormal chromosomes of the EH-GB2 cell line.

\begin{tabular}{|c|c|}
\hline Chromosomes & Markers \\
\hline $\mathrm{M} 1[1 \mathrm{p}+]$ & $\operatorname{der}(1) \mathrm{t}(1 \mathrm{qter} \rightarrow \mathrm{p} 34:: 1 \mathrm{q} 25 \rightarrow \mathrm{qter})$ \\
\hline $\mathrm{M} 2[1 \mathrm{q}-)]$ & $\operatorname{del}(1)(1$ pter $\rightarrow$ q22::1q32 $\rightarrow$ qter $)$ \\
\hline $\mathrm{M} 3[1 \mathrm{q}+]$ & $\operatorname{add}(1)($ pter $\rightarrow$ qter::q21 $\rightarrow$ qter $)$ \\
\hline $\mathrm{M} 4[\mathrm{i}(2 \mathrm{q}))]$ & $\mathrm{i}(2)(\mathrm{qter} \rightarrow \mathrm{p} 10:: \mathrm{q} 10 \rightarrow \mathrm{qter})$ \\
\hline M5[i(2p)] & $\mathrm{i}(2)($ pter $\rightarrow$ p $10:: q 10 \rightarrow$ pter $)$ \\
\hline M6[der(3)] & $\operatorname{der}(3) \mathrm{t}(3 \mathrm{qter} \rightarrow \mathrm{q} 10:: 1 \mathrm{q} 10 \rightarrow \mathrm{qter})$ \\
\hline M7[5p-] & $\operatorname{del}(5)($ qter $\rightarrow$ p 13: $)$ \\
\hline M8[5q- $]$ & $\operatorname{del}(5)($ pter $\rightarrow q 13:)$ \\
\hline М9[6p-] & $\operatorname{del}(6)($ qter $\rightarrow \mathrm{p} 21:)$ \\
\hline $\mathrm{M} 10[7 \mathrm{p}+]$ & $\operatorname{der}(7) t(7 q t e r \rightarrow p 14:: 8 q 11 \rightarrow q$ ter $)$ \\
\hline M11[8q-] & $\operatorname{del}(8)($ pter $\rightarrow q 13:)$ \\
\hline $\mathrm{M} 12[9 \mathrm{q}+)]$ & $\operatorname{add}(9)($ pter $\rightarrow q 10:: ?)$ \\
\hline M13[9p-] & $\operatorname{del}(9)(q \operatorname{ter} \rightarrow \mathrm{p} 12:)$ \\
\hline M14[der(9)] & $\operatorname{der}(9)(: 9 p 12 \rightarrow q t e r:: ?)$ \\
\hline $\mathrm{M} 15[10 \mathrm{q}+]$ & add(10)(pter $\rightarrow$ qter::?) \\
\hline M16[11q-] & $\operatorname{del}(11)($ pter $\rightarrow q 14:)$ \\
\hline $\mathrm{M} 17[14 \mathrm{q}+]$ & add(14)(pter $\rightarrow$ qter::?) \\
\hline M18[15q- $]$ & $\operatorname{del}(15)($ pter $\rightarrow q 15:: q 23 \rightarrow q t e r)$ \\
\hline M19[15q+] & $\operatorname{add}(15)(15 q$ ter $\rightarrow$ p $10:: 22$ p $10 \rightarrow$ qter $)$ \\
\hline $\mathrm{M} 20[16 \mathrm{q}+]$ & add(16)(pter $\rightarrow$ qter::?) \\
\hline M21[18p+] & add(18)(qter $\rightarrow$ pter::?) \\
\hline M22[20q-] & $\operatorname{del}(20)($ pter $\rightarrow q 21$ \\
\hline M23[xq-] & $\operatorname{del}(X)($ pter $\rightarrow q 24:)$ \\
\hline M24[mar1] & $\operatorname{der}(?)$ \\
\hline M25[mar2] & $\operatorname{der}(?)$ \\
\hline M26[dmin] & dmin \\
\hline
\end{tabular}

line established by us may provide an efficient stool for eluding the mechanism of hepatic metastasis of gallbladder cancer.

Metastasis, the spread of malignant cells from a primary tumor to distant sites, poses the biggest problem to cancer treatment and is the main cause of death of cancer patients

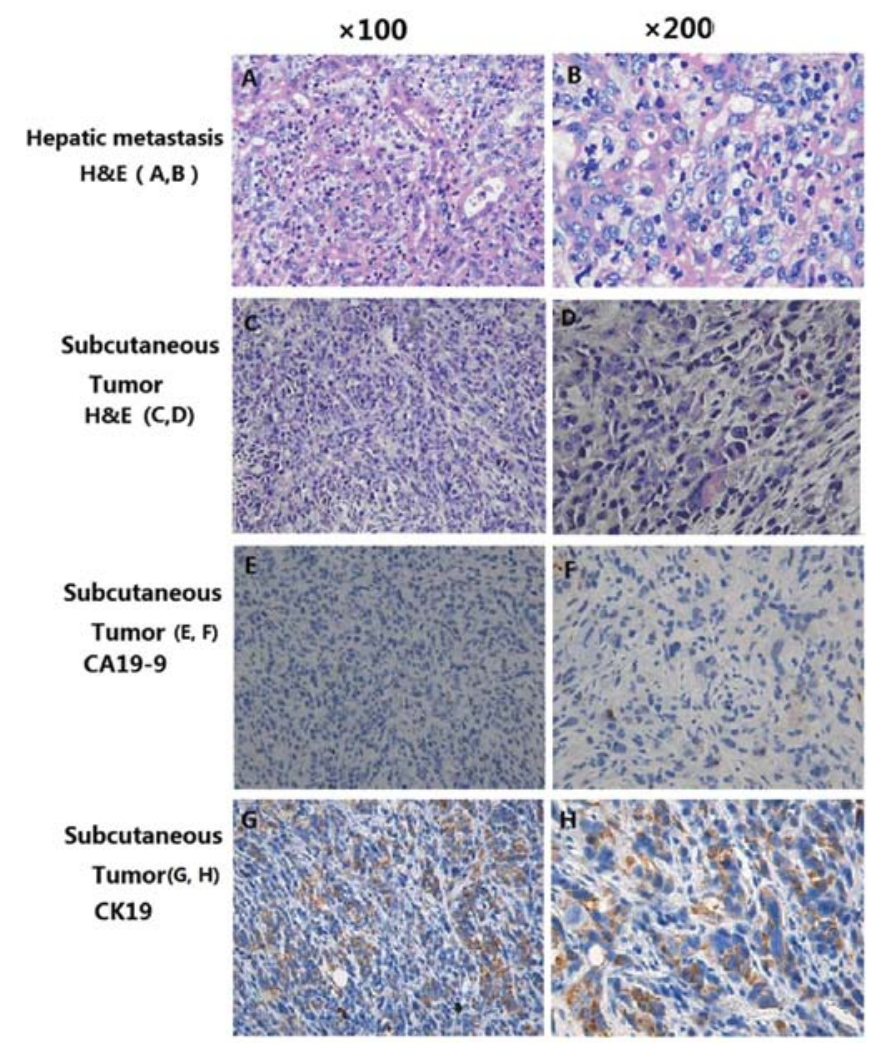

Figure 6. Pathological examination of subcutaneous tumors. Both implanted tumor tissues (C and D) and hepatic metastasis (A and B) have typical pathology characteristics of gallbladder carcinoma (H\&E). All tumor cells have large and deeply stained nuclei, and have a similar shape with the cultured cells under light microscopy. The expression of CA19-9 is negative in the subcutaneous tumor (E and F). But the expression of CK19 is positive (G and $\mathrm{H})$.

(13). In the metastasis process, many potential ways and molecules were involved (13). As a tumor of epithelial origin, distant organ metastasis of gallbladder cancer could be interpreted by epithelial-mesenchymal transition (EMT), which is characterized by the loss of epithelial cell markers of cell-cell adhesion molecules, such as E-cadherin $(14,15)$. EMT is a key step toward cancer metastasis, and many major 
transcription factors were involved (16). Here, we analyzed the expression level of EMT-related reducers or regulators, Snail, Twist, matrix metalloproteinases (MMP)-1, -2, -9 (17-20), E-cadherin (21-23), integrin $\alpha 5$, itergerin $\beta 1$ and VEGF of the EH-GB2 cell line. E-cadherin is an adhesion protein that plays a central part in epithelial morphogenesis. The expression of this protein is down-regulated during the acquisition of metastatic potential at late stages of epithelial tumor progression (24). In this study the expression of E-cadherin and Snail/ Twist in EH-GB2 had a negative relationship; E-cadherin was downregulated and Snail/Twist was up-regulated compared with the control cells. This condition indicates that the downregulation of E-cadherin in EH-GB2 cells occurs through up-regulation of the transcriptional repressors Snail and Twist families (24-26). A series of results in vivo/in vitro indicate that $\mathrm{EH}-\mathrm{GB} 2$ cells have a greater degree of invasive ability than GBC-SD cells. We found MMP-2 and MMP-9 in EH-GB2 have a higher expression level than the positive control GBC-SD cells, indicate that EH-GB2 cell line has more abilities and chances of invasion or metastasis (27-29). Reverse transcription-PCR revealed that MMP-2, -9 mRNA was overexpressed in EH-GB2 than control cells. A woundhealing assay also showed that the migration capacity of EH-GB2 cells was much greater than that of GBC-SD cells. These findings suggest that a highly invasive ability, MMP production, and a migratory ability may be the underlying cause of the increased metastatic potential of EH-GB2 cells.

As with most of the malignant tumors, gallbladder cancer cells can produce various tumor-associated antigens, which function as diagnostic markers or prognostic factors. However, it is discouraging that these antigens have poor specificity and sensitivity targeting to gallbladder cancer. The EH-GB2 cell line produces CA19-9 at high concentrations, although the level of CEA and AFP are at low levels. At present, CA19-9 is the most common tumor marker used in gallbladder cancer. Some previous studies have reported that the overexpression of CA19-9 is an important predictor factor of recurrence and liver metastasis, such as in gallbladder cancer (30), colorectal cancer (31), pancreatic cancer $(32,33)$. CEA is reported to be a cell-to-cell adhesion molecule (34) and therefore reduced CEA expression may facilitate EMT in cells and may increase the invasive ability. The negative expression of AFP may indicate the gallbladder origin of the EH-GB2 cell line. However, we also found the inconsistent expression of CA19-9, positive in the supernatant and negative in the implanted tumor tissue. There are no relative references available to interpret this phenomenon. Maybe the relative gene was lost during cell culture.

To our knowledge, EH-GB2 is the first gallbladder cancer cell line derived from hepatic metastasis that shows frequent EMT and a high metastatic potential. These well-characterized gallbladder cancer cell lines will be useful tool for investigating the metastatic mechanism and biological characteristics of gallbladder cancer, and then to find effective therapeutics.

\section{Acknowledgements}

This study was supported by the National Natural Science Founds for Distinguished Young Scholar (no. 30925035), by the Program of Shanghai Subject Chief Scientist (A type) and by Shanghai Municipal Health Bureau Foundation (no. 2010014).

\section{References}

1. Downing SR, Cadogan KA, Ortega G, et al: Early-stage gallbladder cancer in the surveillance, epidemiology, and end results database: effect of extended surgical resection. Arch Surg 146: 734-738, 2011.

2. Misra S, Chaturvedi A, Misra NC and Sharma ID: Carcinoma of the gallbladder. Lancet Oncol 4: 167-176, 2003.

3. Yildirim E, Celen O, Gulben K and Berberoglu U: The surgical management of incidental gallbladder carcinoma. Eur J Surg Oncol 31: 45-52, 2005.

4. Quan ZW, Yang Y, Li JY, Gong W, Qin YY and Li SG: The mechanisms of somatostatin induced enhanced chemosensitivity of gallbladder cancer cell line to doxorubicin: cell cycle modulation plus target enzyme up-regulation. Biomed Pharmacother 64: 451-457, 2010.

5. Kool M, de Haas M, Scheffer GL, et al: Analysis of expression of cMOAT (MRP2), MRP3, MRP4, and MRP5, homologues of the multidrug resistance-associated protein gene (MRP1), in human cancer cell lines. Cancer Res 57: 3537-3547, 1997.

6. Twentyman PR and Luscombe M: A study of some variables in a tetrazolium dye (MTT) based assay for cell growth and chemosensitivity. Br J Cancer 56: 279-285, 1987.

7. Waha A, Watzka M, Koch A, et al: A rapid and sensitive protocol for competitive reverse transcriptase (cRT) PCR analysis of cellular genes. Brain Pathol 8: 13-18, 1998.

8. Chan KY, Ozcelik H, Cheung AN, Ngan HY and Khoo US: Epigenetic factors controlling the BRCA1 and BRCA2 genes in sporadic ovarian cancer. Cancer Res 62: 4151-4156, 2002.

9. Wang Z, Li Y, Banerjee S, et al: Down-regulation of Notch-1 and Jagged-1 inhibits prostate cancer cell growth, migration and invasion, and induces apoptosis via inactivation of Akt, mTOR, and NF-kappaB signaling pathways. J Cell Biochem 109: 726-736, 2010

10. Rattanasinganchan $\mathrm{P}$, Leelawat $\mathrm{K}$, Treepongkaruna SA, et al: Establishment and characterization of a cholangiocarcinoma cell line (RMCCA-1) from a Thai patient. World J Gastroenterol 12: 6500-6506, 2006.

11. Borensztajn K, Stiekema J, Nijmeijer S, Reitsma PH, Peppelenbosch MP and Spek CA: Factor Xa stimulates proinflammatory and profibrotic responses in fibroblasts via protease-activated receptor-2 activation. Am J Pathol 172: 309-320, 2008

12. Chao TC and Greager JA: Primary carcinoma of the gallbladder. J Surg Oncol 46: 215-221, 1991.

13. Geiger TR and Peeper DS: Metastasis mechanisms. Biochim Biophys Acta 1796: 293-308, 2009.

14. Boyer B, Valles AM and Edme N: Induction and regulation of epithelial-mesenchymal transitions. Biochem Pharmacol 60: 1091-1099, 2000.

15. Klein CA: The biology and analysis of single disseminated tumour cells. Trends Cell Biol 10: 489-493, 2000.

16. Kudo-Saito C, Shirako H, Takeuchi T and Kawakami Y: Cancer metastasis is accelerated through immunosuppression during Snail-induced EMT of cancer cells. Cancer Cell 15: 195-206, 2009.

17. Foda HD and Zucker S: Matrix metalloproteinases in cancer invasion, metastasis and angiogenesis. Drug Discov Today 6: 478-482, 2001

18. Fingleton B: Matrix metalloproteinases: roles in cancer and metastasis. Front Biosci 11: 479-491, 2006.

19. Liu D, Nakano J, Ishikawa S, et al: Overexpression of matrix metalloproteinase-7 (MMP-7) correlates with tumor proliferation, and a poor prognosis in non-small cell lung cancer. Lung Cancer 58: 384-391, 2007.

20. Wang X, Nagase H, Watanabe T, et al: Inhibition of MMP-9 transcription and suppression of tumor metastasis by pyrroleimidazole polyamide. Cancer Sci 101: 759-766, 2010.

21. Onder TT, Gupta PB, Mani SA, Yang J, Lander ES and Weinberg RA: Loss of E-cadherin promotes metastasis via multiple downstream transcriptional pathways. Cancer Res 68: 3645-3654, 2008.

22. Umbas R, Isaacs WB, Bringuier PP, et al: Decreased E-cadherin expression is associated with poor prognosis in patients with prostate cancer. Cancer Res 54: 3929-3933, 1994.

23. Noe V, Fingleton B, Jacobs K, et al: Release of an invasion promoter E-cadherin fragment by matrilysin and stromelysin-1. J Cell Sci 114: 111-118, 2001. 
24. Batlle E, Sancho E, Franci C, et al: The transcription factor snail is a repressor of E-cadherin gene expression in epithelial tumour cells. Nat Cell Biol 2: 84-89, 2000.

25. Yang J, Mani SA, Donaher JL, et al: Twist, a master regulator of morphogenesis, plays an essential role in tumor metastasis. Cell 117: 927-939, 2004.

26. Becker KF, Rosivatz E, Blechschmidt K, Kremmer E, Sarbia M and Hofler H: Analysis of the E-cadherin repressor Snail in primary human cancers. Cells Tissues Organs 185: 204-212, 2007.

27. Tester AM, Ruangpanit N, Anderson RL and Thompson EW: MMP-9 secretion and MMP-2 activation distinguish invasive and metastatic sublines of a mouse mammary carcinoma system showing epithelial-mesenchymal transition traits. Clin Exp Metastasis 18: 553-560, 2000.

28. Duong TD and Erickson CA: MMP-2 plays an essential role in producing epithelial-mesenchymal transformations in the avian embryo. Dev Dyn 229: 42-53, 2004.
29. Miyoshi A, Kitajima Y, Sumi K, et al: Snail and SIP1 increase cancer invasion by upregulating MMP family in hepatocellular carcinoma cells. Br J Cancer 90: 1265-1273, 2004

30. Bartlett DL: Gallbladder cancer. Semin Surg Oncol 19: 145-155, 2000.

31. Yakabe T, Nakafusa Y, Sumi K, et al: Clinical significance of CEA and CA19-9 in postoperative follow-up of colorectal cancer. Ann Surg Oncol 17: 2349-2356, 2010.

32. Haglund C, Roberts PJ, Kuusela P, Scheinin TM, Makela O and Jalanko H: Evaluation of CA 19-9 as a serum tumour marker in pancreatic cancer. Br J Cancer 53: 197-202, 1986.

33. Haglund C: Tumour marker antigen CA125 in pancreatic cancer: a comparison with CA19-9 and CEA. Br J Cancer 54: 897-901, 1986.

34. Jessup JM, Ishii S, Mitzoi T, Edmiston KH and Shoji Y: Carcinoembryonic antigen facilitates experimental metastasis through a mechanism that does not involve adhesion to liver cells. Clin Exp Metastasis 17: 481-488, 1999. 